\title{
25 Research Suare \\ Can Primary Healthcare be Protected as a Public Good in Lebanon Today?
}

Randa Sami Hamadeh

Ministry of Public Health, Beirut

Ola Ali Kdouh ( $\nabla$ olakdouh@gmail.com )

Ministry of Public Health https://orcid.org/0000-0002-3186-9986

Rawan Hammoud

Ministry of Public Health, Beirut

Enrica Leresche

London School of Hygiene and Tropical Medicine

Jennifer Leaning

Harvard Françoix-Xavier Bagnoud Center for Health and Human Rights, Boston

\section{Commentary}

Keywords: Primary Health Care, Covid-19, Protracted conflict, Lebanon, health system resilience, disaster response

Posted Date: September 14th, 2020

DOI: https://doi.org/10.21203/rs.3.rs-73442/v1

License: (c) (i) This work is licensed under a Creative Commons Attribution 4.0 International License. Read Full License

Version of Record: A version of this preprint was published at Conflict and Health on April 7th, 2021. See the published version at https://doi.org/10.1186/s13031-021-00359-4. 


\section{Abstract}

When Lebanon's primary healthcare network meets Covid-19 in the midst of an economic collapse and a disaster, what are the crucial questions?

In this commentary we look at the impact of three profound shocks (the Lebanese civil war, the Syrian refugee crisis, and the current economic breakdown) which the Lebanese primary healthcare network (PHCN) has met in the last half century. We examine the past and current constraints that these events have imposed on the capacity of the PHCN to respond to the Covid-19 pandemic. In the context of impending economic collapse, rising social and political tensions-and now the devastating explosion in the capital on 4 August 2020-we identify the broader and deeper issues at stake as the Lebanese primary health care network struggles to fulfil its mandate to support the delivery of essential primary health care to Lebanon's most vulnerable populations. Our finding is that in a protracted conflict, such as the one defining the circumstances of Lebanon now, access to health care persists for the people as one safeguard in which social and moral continuity can be anchored and protected.

\section{Background}

The Lebanese pluralistic society has often managed to maintain a relative equilibrium in the midst of very turbulent times. Following the independence of the country in 1943, an agreement was shaped through the National Pact that defined a sectarian distribution of powers, which had been initiated under the French mandate [1]. At the end of the Lebanese civil war in 1990, the National Pact was replaced by the Taef Agreement along the same lines [1]. This sectarian distribution of political powers has become over the years increasingly dysfunctional and kleptocratic [2,3]. Periodically, the country's autonomy has also been threatened or pressurized by regional and international nation-states $[1,3]$. The country now faces severe threats to its survival from impending economic collapse and hyper-inflation, factors brought on by grave failures in governance to protect public goods. The Covid-19 pandemic is challenging the frailties of the public health system, chronically underfunded by the Lebanese government for its routine obligations to care for the populations of poor Lebanese and of 1.5 million Syrian refugees who fled Syria from 2011 through 2014 [4, 5].

Protracted conflicts arise in multiples of existential shocks-active armed conflicts (non-international or international), social strife resulting from poorly resolved past conflicts, governmental collapse, systemwide economic failure, hostile invasions, mass refugee influx, massively destructive disasters, large-scale internal displacement occasioned by local conflict or climate-driven assaults on livelihoods, and, rarely, pandemics. These shocks may occur sequentially or at times accumulate in a short time frame, often because they may be related to or they increase the negative dynamics of previous calamities. The humanitarian community is only just beginning to recognize these complexities and their implications for relief and development. These questions were recently examined (by the International Committee of the Red Cross) to identify key characteristics of any protracted conflict, all of which are active in the case of Lebanon [6]. A protracted conflict claims longevity, either as one that persists for decades or one that 
merges and entangles with others within one country. It fragments and mutates, engaging new armed groups, political factions, disruptions, and re-framing of goals. It arises episodically, with spikes of distress or violence that are not of equal intensity. It is internationalized, prompting other States to intervene in various forms. It imposes a cumulative impact, wherein infrastructure is degraded, utilities and services decay, and living conditions decline. It induces pervasive fragility of governance and reduced capacity to withstand economic and political shocks or massive disasters. And over time it intensifies the suffering of its people, who move to escape one shock and then another, resulting in a rising number of impoverished people moving within or beyond national borders.

The interactive relationship between protracted conflicts and public health has been described in the past decades, including the direct and indirect consequences that conflicts impose on health, as well as the notion of "breakdown" of societies where civilians bear the heaviest part of the burden [6-8]. In such contexts, the efforts undertaken require "working short and working long"[6]. From this perspective, the role of a public health system (often buttressed by local or international non- governmental organizations) can rapidly become compromised but also may persist as an important beacon of hope, healing, aspiration, and persistent value given to human life. The peer-reviewed literature on this topic is scant but include insights captured in accounts of humanitarians and human rights observers in the wars and crises, as well as in historical accounts of protracted conflicts (including the many post-colonial wars) arising in the decades after World War II.

One major constraint of the literature on this subject, however, is the difficulty of analyzing and measuring events as they happen, forcing a reliance on retrospective accounts. In the case of Lebanon today, there might be an opportunity to explore in real time important questions related to the public health decisions that have to be made by those in the primary health care network ( $\mathrm{PHCN}$ ) as they face a deep and multi-faceted crisis [5]. These important questions for Lebanon relate to the need to recognize the trade-offs embedded in any decisions taken to respond to Covid-19 as an acute disaster unfolds, and how these can be negotiated in both the short and long term. These constraints include the necessity to integrate local knowledge and to build partnerships; while aiming to respond to acute needs, to diminish the cumulative impact in a population affected by different layers of crises, and to discern what has to be addressed immediately, while building longer term resilience [6,9]. These questions now confront those delivering primary health care in Lebanon. Their approach, strategies, and compromises are analysed in this commentary.

\section{Main Text}

In this section we document the three main shocks that the Lebanese primary health care network (PHCN) has been dealing with since 1975. Then, we analyse how this network has been adapting to such constraints through 2019, and how they now confront significant trade-offs in crafting an appropriate response to the Covid-19 crisis pandemic when the economy is collapsing and the Beirut port and half the city lie in ruins. 


\section{The shock of the Lebanese civil war (1975-1990)}

The Lebanese civil war resulted in numerous deaths, injuries, and economic losses as it succeeded to "put an end to the prosperity and economic growth witnessed in Lebanon since the 1950s, and had a catastrophic impact on both the private and the public sectors"[1]. The civil war seriously affected the capacity of the Ministry of Public Health (MoPH) and increased its reliance on disparate non-state actors and private providers $[4,5,10,11]$. The war disrupted previous efforts to establish an integrated healthcare system and forced upon Lebanon a social organisation of health care based on sectarian lines $[1,3,10]$. The war also created in each region substantial opportunity for an increasing number of non-governmental and private actors in the health care sector, who continue to play an important role in providing primary health care $[4,5]$. The current overall health system remains very hospital centred and the private system has become the key service provider $[4,5,11]$. The result of the post-civil war arrangement is that the provision of health care has devolved to fragmented sub-systems, most of them private but including the public system as well. These arrangements deliver health care through separate mechanisms to various populations of interest, relying on the 70 plus years of support from the United Nations Relief and Works Agency (UNRWA) to cover the health needs of the chronically impoverished Palestinian refugees $[4,5,11]$. Consequently, a people-centred and patient-centred approach has proved difficult to build - especially at the level of primary care $[4,5,11]$.

The distortions in funding primary health care relate to these post-civil war arrangements. For vulnerable populations, the prevailing pattern is a minimal government system of primary health care for poor Lebanese, for Palestinian refugees with support from UNRWA and now for Syrian refugees partly subsidized by UNHCR; while Lebanese employed in the formal sector benefit from a combination of national funds and expensive private system of care $[5,10]$. The costs of access to health care through out-of-pocket (OOP) expenditures has placed a disproportionate burden on the most vulnerable [5, 11]. The law to provide for one single pool of funds to cover the entire Lebanese population has never been passed due to conflicting interests [4]. The MoPH is the funder of last resort for over 50 percent of the total Lebanese population who lack other forms of insurance, resulting in a heavy drain on public funds to cover mainly private hospital costs $[4,5,11]$. In addition, most insurance schemes exclude outpatient services (including both consultations and diagnostics) which then must be covered, in general, by OOP payments. The result is that to access most outpatient services, patients have to pay out of pocket at point of care, a practice that creates financial barriers to seeking any form of primary care [1]. Public health centres in the MoPH network receive support from the MoPH in terms of supplies, so the costs to the patient are somewhat subsidized. In contrast to the 79 percent of the MoPH budget allocated to reimburse contracts with hospital services, it is estimated that only 5 percent of the MoPH budget is allocated for prevention and primary health care services [1].

\section{The shock of the Syrian Crisis (2011-2020)}


After the outbreak of the Syrian civil war, the influx of over one million Syrian refugees into Lebanon increased the population by over $30 \%[11,12]$. The government established a "no-camp" policy which aimed at integrating refugees into the communities and existing systems, even when these were already weakened or failing $[4,11]$. This strategy resulted in a number of service and financial complexities that posed many challenges to the MoPH. First, an increased population of over one million impoverished refugees had to be covered $[5,11]$. The arrival of Syrian refugees has increased the population mainly in previously vulnerable areas, since they have settled within the poorest Lebanese communities [11]. As a result, this crisis imposed an important new burden on the Lebanese PHC system by drastically increasing its catchment population in the most fragile areas of the system $[4,11]$. As the refugee population rose, the percentage of Syrian refugees in the PHC network increased from 12\% (in 2012) to $46 \%$ (in 2018). This increase varied by regions, so that some impoverished areas were more affected than others. The overall result was an accentuation of community tensions between and among all these vulnerable communities [4]. Second, the diversity of actors increased. The Syrian crisis brought an influx of local and international non-governmental organizations (NGOs) and donors, resulting in further fragmentation of the systems of care [11]. This increasingly complex system potentially created overlaps for patients as well as providers $[4,11]$. To access PHCs, Lebanese pay a discounted rate compensated by the MoPH through in-kind support and registered Syrian refugees benefit from a preferential rate compensated by financial support from the UNHCR $[4,11]$. The humanitarian response and the MoPH support and funding, however, have not been sufficient to decrease inequalities and ensure access to basic health services for the most vulnerable [11].

\section{The shock of the economic crisis (October 2019-today)}

In October 2019, Lebanon's economic crisis developed into a full-blown economic collapse [2]. Loss of confidence in the local currency led to effective devaluation of the market rate for Lebanese Lira and shortages of US dollars in the Lebanese banks [2]. Unemployment rates skyrocketed as hundreds of businesses closed down [3]. These developments in turn created shortages in basic supplies and inflation in prices of goods. Economic experts say Lebanon will experience a deep recession and a double-digit contraction in the economy equivalent to what the United States experienced during the Great Depression [2]. In this projection, poverty rates could rise to include more than $45 \%$ percent of the Lebanese population, leaving 1.6 million people unable to afford food and basic nonfood items $[2,5]$. By the end of 2020 , some projections estimate that poverty rates among Lebanese could reach $75 \%$ of the population [3].

\section{How did the public PHC network adapt to the different waves of shocks?}

In this section we look at how each shock has transformed the structure and the capacities of the PHCN between 1990 and today, and we analyse why these changes are fundamental in understanding what 
form of Covid-19 response might make sense in this context.

Post-civil war reforms for the PHC were proposed by the MoPH to shift from an emphasis on curative to preventive care. The intent was to regulate and harmonize the emerging PHC network and to build a public service promoting health and protecting the population based on the Alma Ata Declaration [1]. These reforms took place between 1998 and 2007 in the midst of political turmoil and successive conflicts, which led to repeated economic recessions and progressively decreasing funds allocated to the public health system [1]. In these years, 25 percent of the MoPH staff who retired were not replaced and difficulties in coordinating funding were intensified by political differences [1]. To institute reforms such as a shift to preventive care delivered by the PHC network was also a difficult task in some geographic areas where there existed few options for curative care, thus reducing the capacity to refer to a close higher echelon of care [4]. Despite these constraints, the national Primary Healthcare Network (PHCN) was established in 1996 with 19 Primary Healthcare Centres [1, 4]. Today the network includes 237 PHC centres distributed across Lebanon, serving over 1 million beneficiaries annually including both poor Lebanese and Syrian refugee populations [12]. The PHC centres are run by NGOs (67\%), municipalities (20\%), academia (1\%) or governmental institutions (12\%) [12]. Each centre provides basic PHC services, while the MoPH supports some PHC centres through in-kind contributions. In return, the contracted centres commit to provide the basic services required by the $\mathrm{MoPH}$ at discounted rate; to adhere to the regulations on the national immunization calendar and essential medications; and to submit monthly reports to the MoPH [12].

To meet the international goal of making it possible for the over one million Syrian refugees to remain in Lebanon, the international community raised substantial resources for housing and health care which were funneled to the national government $[4,12]$. Key to this effort was reducing the tension between populations and supporting the delivery of healthcare services $[4,11]$. These funds were additional to ongoing support from existing donors and brought new grants and donors. In terms of PHC, some very important new supports were provided to mitigate the crisis effects on the most impoverished Lebanese, while helping to building a longer term program with a package of subsidized care for PHC services including mental health [4]. However, in 2019, an analysis of some key achievements of this project showed that important gaps remained, including the lack of coverage of urgent pressing needs related to outpatient consultations and screening and diagnostic tests [4]. Several important systemic issues in the PHC network documented since 2009 remain and include the complex referral system; an inadequate balance of different types of human resources for health needed at the primary level of care coupled with significant turnover; and challenges posed in trying to manage the drug supply chains in the network [1, 4]. Yet these historically grounded constraints and the weight of the current crises have not extinguished the vision of Universal Health coverage at the core of the MoPH strategy [11].

In an unprecedented way, the cummulative effects of these different simultaneous crises are now threatening the progress made in shifting the health response towards $\mathrm{PHC}$ and in ensuring that there are mechanisms in place to account for the most vulnerable populations. At the structural level, these crises have markedly reduced the capacity to import essential drugs, medical supplies and equipment [5]. 
Access to basic services such as water and electricity has been reduced due to shortages in gasoline and diesel resulting from the inflation, the shortage of US dollars, and the consequent inability to import from abroad. Hospitals and healthcare facilities are unable to operate at full capacity and are using their scarce resources to maintain utilities (in terms of water and electricity) while accepting only patients in need of emergency care shutting down operations for cold cases.

The drastic reduction of purchasing power as a result of higher unemployment and rising prices has led to major difficulties in maintaining a minimum livelihood [3]. As people struggle to make ends meet and to procure basic food items, accessing healthcare services has became a luxury and an increasingly larger proportion of the population has became priced out of even the subsidized health care services. As the proportion of impoverished Lebanese is rising, the populations at the edge of poverty are more likely to neglect preventive care or to try to self-manage their chronic diseases, since clinic outpatient care is not covered by insurance schemes or the government. As a result, people delay seeking care until their condition is critical and then they present directly to public hospitals where secondary care is to be covered by the MoPH (for the most vulnerable Lebanese) and by the national fund or private insurances (if people are employed) $[5,11]$. Yet in current circumstances, as unemployment rises and families inevitably lose their associated health insurance, the government and the MoPH risks being saddled with covering the secondary care of a much larger proportion of the population in an increasingly critical state.

As for the primary healthcare sector, it has been badly battered by the economic crisis on multiple levels. Domestic funding for the primary healthcare sector has been either frozen or rescinded. Existing budgets allocated to vaccine, chronic and essential drugs, and reproductive health supplies procurement for the national PHC network are not being transferred or disbursed by the Ministry of Finance due to lack of available funds. The PHC department at the MoPH itself has not received funding-and this has been the case for almost two years. This absence of regular funding is leading to stock-outs in medication at the level of the PHC centres. In order to prevent discontinuation of medication at the level of the beneficiaries, the government has temporarily shifted the burden of procuring the medicine to the PHC centres and their related NGOs, for what is termed "the interim stock-out period." To mitigate this issue, the MoPH is working with EU- MADAD initiative, UNICEF, UNFPA, WHO, and UNHCR to cover this gap and fund the procurement of the vaccines and drugs for the national PHC network, which benefits both Syrian refugees and the vulnerable host Lebanese population. These entities are already playing a major role in the COVID-19 response through procuring Personal Protective Equipment (PPE) for the PHC network. Although the international UN agencies are stepping up to fill these gaps, these emergency measures serve to create further dependency in Lebanon on external funding in the public healthcare sector, which may have a spill-over effects in shaping the funding of the healthcare system in Lebanon in the future.

In addition, operational costs for the PHC network are increasing while resources are dwindling, particularly the electricity costs at the central drug warehouse (essential to maintaining the cold chain) and the transportation costs to conduct the quality monitoring field visits. As for human resources at the PHC department, funding has almost disappeared with the existing team now only one third of what it was two years ago. This reduction in staff leads to decreased ability to conduct quality monitoring and 
follow-up within an increasingly more stressed PHC network. At the level of the PHC centres, operational costs have also drastically gone up. The PHC centres are having to pay more in terms of (i) supplies which are all imported on the dollar rate, and (ii) generators and back-up electricity required by daily long outages. In addition, revenues have gone down as poverty rates increase and beneficiaries can no longer afford the already subsidized fees. As a result, the PHC centres are resorting to measures to decrease their operational cost in others ways such as (i) giving half salaries or turning full time positions into part time; (ii) stopping imports of expensive supplies; and (iii) switching to more affordable supplies like chlorine for sterilization instead of other disinfectants. PHC centres and NGOs are also requesting an increase in the consultation fee at the PHC network to match the $40 \%$ increase in the private sector as announced by the Order of Physicians. This request has been met with stark rejection at the level of the $\mathrm{MoPH}$ which is keen on maintaining low fees and securing the access of the vulnerable population to these essential services. It is expected in the near future that some PHC centres, particularly those in rural areas or run by small NGOs, would close. Other large NGOs might merge with PHC centres to reduce costs.

On August 4, 2'750 tons of ammonium nitrate left "lying around unsafely for the better part of a decade"[3] exploded in the port of Beirut. The powerful blast led to at least 180 deaths and an estimated 6,000 people injured. Over 110 people remain missing and hundreds of thousands of people have been left homeless in the capital city. At least three hospitals, 12 primary healthcare centres and the MoPH main warehouse (located at less than $3 \mathrm{~km}$ away from the blast epicentre) have been severely damaged. The blast has destroyed five out of seven UNICEF-supported vaccine cold rooms. Members of the MoPH team writing this article have been trying to salvage $90 \%$ of the stock in the 72 hours following the disaster, which with the support of UNICEF need to be relocated as quicky as possible. The violent destruction of these core assets contributes to further disable the health system, already crippled by the shortages in fuel, electricity, medical supplies and water which have been affecting both the private and the public systems for months [5]. When hospitals were not rendered partially or completely disfunctional by the blast and fires, they were rapidly overwhelmed by injured people. The explosions also destroyed ten containers of personal protective equipment (PPE), which remain essential for the national Covid-19 response.

Lebanon, still suffering from the divisions of the civil war, heavily affected by the Syrian conflict, and in the past few months increasingly oppressed by a crumbling economy and a spreading pandemic, now faces a ruinous explosion in the heart of its country whose force is said to be equivalent to $1 / 10$ of the blast effects of the atomic bomb dropped on Hiroshima. What sort of adequate primary health care response can be designed to respond to Covid-19 in such an apocalyptic situation?

\section{Conclusion}

\section{What are the crucial questions related to the Covid-19 response in the midst of sudden disaster?}


On 21 February 2020, the first case of Covid-19 was identified in Lebanon [5]. On 12 August, 7'121 cases were confirmed as well as 87 deaths. Politically, the situation has now become much more complex since the first cases appeared in February. The attention to Covid-19 has virtually disappeared, case counts are rising, and hospitals have much less capacity than before since injuries from angry protests and unrest are now contributing to the initial heavy load of injured from the disaster.

In the graphs below, we observe that the most affected districts include Central Lebanon (encompassing the city of Beirut) as well as areas where vulnerable Lebanese and Syrian refugees live in the North, the South, and the Beqaa. The cases detected seem to have been occurring in three successive waves.

The trends in the pandemic in Lebanon suggest that its evolution is not fully clear and ascertainment issues (testing, contract tracing, isolation) may not be sufficient to contain the disease, especially because the efforts of the health system today might converge towards taking care of the injured from the blasts and re-constituting the hospital infrastructure.

In mid July, the weekly cases increased dramatically, with indications that clusters had occurred among the returning Lebanese disapora who were less abiding by masks or social distancing and possibly among cleaning workers. At this stage, when the numbers may be rising but would still be manageable within the current system, it is crucial to examine how key challenges posed by the Covid-19 pandemic can be met in the face of the ongoing severe degradation of the economy, the declining capacities of the health system and the evolving disaster response. What role might the PHCN play to support the Covid-19 response while maintaining basic service functions when hospitals are now either partially distroyed or overwhelmed in responding to the victims of the blasts and of the protests?

In this complex situation and based on the historical mission and current intent of the PHCN, the response strategy for the public health centres must aim first to ensure that the PHCN can meet the most urgent pandemic needs while maintaining a coherent short and longer-term response in terms of access to essential services for the most vulnerable, including people who have lost everything in the explosions in Beirut. The empirical context described above would suggest four sets of pivotal questions to answer in terms of building a coherent evidence-based response.

The first set of questions relates to the risks posed by Covid-19 and the health system's capacity to detect, trace, refer, and protect the populations in a fragmented PHC network that faces narrowing constraints in service coordination. Information and seasoned assessments from the health sector are needed to understand what is currently feasible in terms of identification, referals and coordination in the current PHC network, in order to avoid a sharp increase of Covid-19 cases following the disaster response.

The second set of questions relates to the capacities of facilities in the network to deal with key gaps --in human resources, laboratory capacities, supply chains and essential stocks of medications and materials - and whether it is justified in such a situation to shift these scarce resources towards a Covid-19 response at the level of the PHCN. 
The third set of questions relates to the population and to the need to understand whether their most essential primary health care needs can be met while focusing on a Covid-19 response at the level of the PHC network, especially during the extended time and effort it will now take to mount an adequate disaster response and meet the health and mental health needs of the injured survivors and their families. These issues require understanding the health and social impacts of not meeting essential needs and the potential for social breakdown that such decisions or outcomes might trigger among the most vulnerable in the longer run. This third set of questions devolves into one main one: Is failing to meet several essential needs in a trade-off made to respond to Covid-19 actually an option in the fragile social and disaster-stunned context of Lebanon today?

The fourth set of questions relate to how the international supports to the disaster are organized and channelled. The crucial question here is whether such emergency supports take into account the broader picture: The need to prevent the spread of Covid-19 cases and to ensure essential access to services at the level of PHCs for all populations trapped in this protracted conflict in the short and long run. Several issues make this crucial question more prominent. One important local constraint is the utter absence of effective leadership and the reciprocal complete lack of citizen trust in the capacity of the government. So the population as a whole, without an adequate spokesperson, might have difficulty in clarifiying to the humanitarian agencies this urgent need to protect primary health care and preventive services and to protect public health as a public good, including work to contain the pandemic. Historically, humanitarian responses to disasters in fragile states often drain resources from local priorities. In the case of Lebanon today, the local longer term priorities might be ignored in an attempt to avoid the untrusted governamental structures to respond to this disaster. Yet a humanitarian disaster response that did not protect the efforts and the results reached by the PHCN under the lead of the MoPH PHC team over the past decade would fail to build the ground for a longer term solution. In a fortunate irony, since Lebanon has been deeply reliant on international aid of all kinds for decades, many of the outside humanitarian responders will already have forged established connections with local health care and local humanitarian organizations throughout the country. In this fraught context, it will be essential to understand how the international aid response rescognizes the need to work both short and long. It is also important to look at whether this support will be sustained once the media coverage ceases to bring the world's attention to Lebanon.

All these issues collide and arise because Lebanon is deeply in the midst of a protracted conflict. And the finding from analysis of these protracted conflicts and disasters is that health care proves to be pivotal in maintaining the morale of ordinary people even as they suffer. The questions and options detailed above link directly to how the PHCN defines its role and actualizes it in ways that maintain a sense of dignity and hope for the Lebanese population in the current circumstances.

This commentary was written by the MoPH PHC team in Lebanon and the Global health team of experts in collaboration with two academic researchers. This team is currently developing a strategy to respond to the questions shared above through a formal field empirical research. The group of authors involved in 
this commentary are willing and open to develop a precise response to these crucial questions through an empirical process and in a collaborative way .

\section{Abbreviations}

\begin{tabular}{ll} 
EU-MADAD & European Union Regional Trust Fund in Response to the Syrian Crisis \\
\hline ICRC & International Committee of the Red Cross \\
\hline MoPH & Ministry of Public Health \\
\hline NGO & Non-Governmental Organization \\
\hline OOP & Out-of-Pocket \\
\hline PHC & Primary Health Care \\
\hline PHCN & Primary Health Care Network \\
\hline PPE & Personal Protective Equipment \\
\hline UN & United Nations \\
\hline UNFPA & United Nations Populations Fund \\
\hline UNHCR & Office of the United Nations High Commissioner for Refugees \\
\hline UNRWA & United Nations Works and Reliefs Agency for Palestinian Refugees \\
\hline US & United States \\
\hline WHO & World Health Organization
\end{tabular}

\section{Declarations}

Ethics approval and consent to participate

Not applicable

\section{Consent for publication}

Not applicable

\section{Availability of supporting data}

All articles used as reference were available in open source. 


\section{Competing interests}

The authors declare that they have no competing interests

\section{Funding}

No funding was received to write or publish this Commentary.

\section{Authors' contributions}

All authors participated equally in the review of the literature, in the discussions, in structuring the commentary, and contributed to the writing of all sections of this paper.

\section{Acknowledgements}

Not Applicable

\section{References}

1. Ammar W. Health Beyond Politics. 2009.

2. ARI. Statement 7th January 2020: Lebanon's Economic Crisis: A Ten Point Action Plan for Avoiding a Lost Decade. Arab Reform Initiative (ARI), 2020.

3. No way to run a country. A big blast should lead to big change in Lebanon. The Economist Group Limited. August 8, 2020.

4. Hemadeh R, Hammoud R, Kdouh O. Lebanon's essential health care benefit package: A gateway for universal health coverage. The International Journal of Health Planning and Management, 2019. 34(4): p. e1921-e1936.

5. DeJong J, The Challenges of a Public Health Approach to COVID-19 Amid Crises in Lebanon. Middle East Report Online, May 08, 2020.

6. ICRC, Protracted conflict and Humanitarian action: some recent ICRC experiences. International Committee of the Red Cross, Geneva, 2016.

7. Leaning J, Guha-Sapir D. Natural disasters, armed conflict, and public health. N Engl J Med. 2013;369(19):1836-42.

8. Garry S, Checchi F. Armed conflict and public health: into the 21st century. Journal of public health (Oxford, England), 2019.

9. Leresche $\mathrm{E}$, et al. Conducting operational research in humanitarian settings: is there a shared path for humanitarians, national public health authorities and academics? Conflict Health. 2020;14(1):25. 
10. Chen B, Cammett M. Informal Politics and Inequity of Access to Health Care in Lebanon. Int J Equity Health. 2012;11:23.

11. Blanchet K, Fouad FM, Pherali T. Syrian refugees in Lebanon: the search for universal health coverage. Conflict health. 2016;10:12-2.

12. GoL and UN, Lebanon Crisis Response Plan 2017-2020 (2018 update). Government of Lebanon and United Nations, 2018.

\section{Figures}

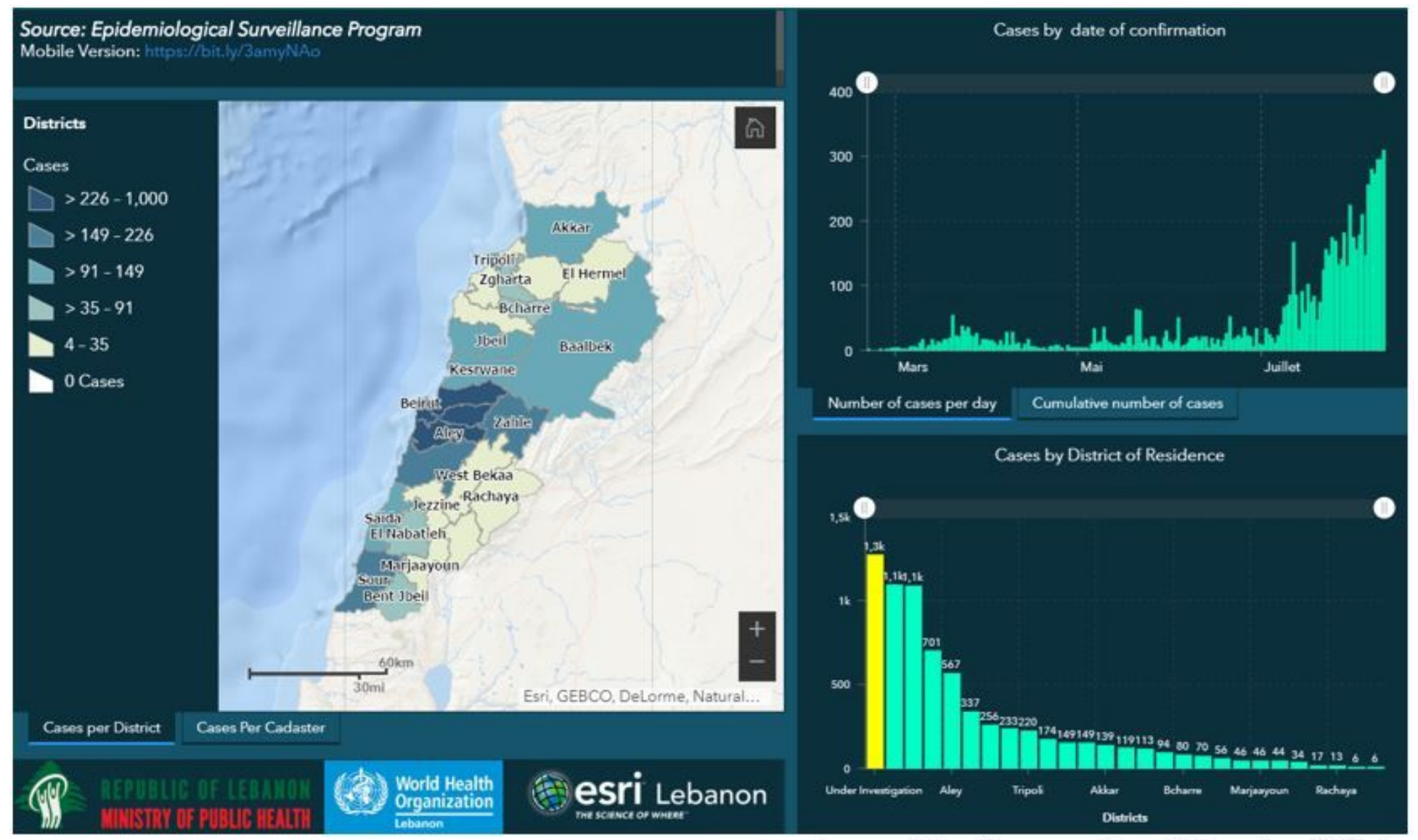

Source : https://www.moph.gov.lb/maps/covid19.php

\section{Figure 1}

The evolution of the Covid-19 pandemic in Lebanon 